\title{
Alguns aportes sobre a clínica desconcertante da Devolução de crianças adotadas: o mesmo e o outro ${ }^{1}$
}

\section{Maria Luiza de Assis Moura Ghirardi ${ }^{2}$}

O tema da adoção de crianças nos remete às representações de um estrangeiro que se insere no núcleo familiar trazendo na bagagem uma história, uma origem e uma dimensão de radical alteridade. Localizada ao longo da história da humanidade, a adoção realça e intensifica afetos que são constituintes do humano em seu inexorável arcaísmo, tais como o desamparo, o abandono, a rejeição. De maneira análoga, a violência, o abuso, a negligência - experiências potencialmente traumáticas que incidem sobre os psiquismos ainda em constituição - desafiam, na contemporaneidade, a clínica psicanalítica e portanto, o psicanalista, a um posicionamento ético, político e social. Inquietante realidade que atravessa o encontro - e tantas vezes o desencontro- entre humanos com suas aproximações e distanciamentos, seus conflitos, suas impotências e angústias. A clínica da adoção conta histórias das variadas formas de sofrimento em que esse estrangeiro pode travestir-se de inquietante e sinistro, revelando o assombro diante do encontro fracassado e da “devolução" daquela criança anteriormente adotada. O desconcerto com a devolução poderá então ser equiparado ao unheimlich, experiência suscitada no adotante em sua relação com a criança; na criança, quando já não se reconhece com seus pais, nos profissionais que acompanham e/ou decidem sobre o destino daquela criança e, sobretudo, no analista, com seus sentimentos contratransferenciais, vividos no contato com aqueles que portam diversos graus de sofrimento com a adoção.

Do ponto de vista legal, a sentença da adoção é irrevogável. Porém, quando a devolução se apresenta no âmbito jurídico, em geral, adota-se o procedimento de suspensão do poder familiar vigente e a criança (ou adolescente) é acolhida - ou re-acolhida em alguns casos - em uma instituição abrigo. O objetivo desse acolhimento é evitar que ela continue em um núcleo familiar que a rejeita, ou se torne vítima de maus tratos.

\footnotetext{
${ }^{1}$ Este trabalho foi apresentado na mesa "Adoção e seus desconcertos" com Gisele Câmara Groeninga no I Simpósio Bienal "O mesmo, o outro: Psicanálise em movimento" da Sociedade Brasileira de Psicanálise de São Paulo.

${ }^{2}$ Psicanalista pelo Instituto Sedes Sapientiae, Membro filiado ao Instituto Durval Marcondes da Sociedade de Psicanálise de São Paulo
} 
A experiência em torno da devolução tem também estatuto psíquico, e pode ser percebida como uma fantasia intrínseca ao campo da adoção e dela faz parte. Nesse sentido, a devolução será sempre um fato possível em algum momento e fantasiado em outro, constituindo parte da estrutura vincular da família adotiva e também do psiquismo de cada um de seus membros. Sendo assim, a fantasia de devolução poderá surgir com maior ou menor intensidade, direta ou indiretamente, tanto nos pais como nos filhos, sobretudo, em momentos de conflitos entre eles. O tema, portanto, desperta inquietude e estranhamento ao suscitar expressões do funcionamento psíquico primitivo, das angustias inomináveis. Pode-se dizer que a devolução em alguns casos, significa um meta-abandono, uma vez que a criança pode ter passado por outra situação anterior que a remete aos sentimentos de rejeição e abandono.

Logo após ter recebido o convite para compor esta mesa, surpreendi-me com o recebimento de um encaminhamento, em que a complexa situação da família era vivida pelo casal e um filho adolescente que havia decidido junto à Promotoria, deixar a casa dos pais adotivos e ir para uma instituição de acolhimento. Fruto de um período de 1 1/2 ano s de intensos conflitos, agressões mutuas e violência na família, a decisão do adolescente gerou nos pais uma ferida narcísica de grandes proporções, desencadeando muita raiva e rejeição. Os pais o responsabilizavam por ingratidão, agressividade, desrespeito à autoridade, roubo, mentiras. Ele se tornara o estranho/familiar, nos moldes em que Freud descreveu o Sinistro em 1919. Diziam com muita hostilidade que ele precisaria mudar muito para poder voltar para casa. Às vezes esse "muito" tornava-se "um pouquinho mais", significando exigências máximas para as "mínimas diferenças", como nos dizia Freud, referindo-se ao narcisismo exigente, de assimilação de Outro que se quer que seja o Mesmo...

Lembro aqui de Todorov (2016) que, ao traçar uma tipologia das relações com outrem, diz:

Nossa relação com o outro não se dá em uma única dimensão. Para dar conta das diferenças existentes no real, é preciso distinguir entre pelo menos três eixos, nos quais pode ser situada a problemática da alteridade. Primeiramente um julgamento em que o outro é bom ou mau, gosto dele ou não gosto dele, me é igual ou me é inferior. Em segundo lugar, há a ação de aproximação ou distanciamento em relação ao outro: identifico-me ou não com ele, adoto seus valores; Ou então assimilo o outro, impondo-lhe minha própria imagem, gradiente entre a submissão ao outro e a submissão do outro (p.269). 
Essa clínica da chamada 'devolução' frequentemente se impõe para além dos limites do consultório e nos convoca de maneira muito especial, por demandar intervenções atravessadas por Outros e Outras instituições. Dessa forma, a escuta poderá se expandir para âmbitos diversos como o judiciário, a rede pública de apoio e assistência social, o Creas e a Instituição de acolhimento, abarcando instâncias que, supostamente, trabalham numa dimensão multidisciplinar. Para efeito desta apresentação, quero deter-me ao aspecto do atendimento clínico em si, contemplando mais especificamente as intensas experiências subjetivas diante das quais o analista se vê convocado, ou seja, o desconcerto, a contratransferência, e o assombro, termo cunhado por Nosek ao ressaltar mais apropriadamente, a disposição, a abertura necessária do analista para captar, e assim vivenciar, as intensas angustias dos protagonistas envolvidos.

Em minha experiência, quando uma situação ligada à devolução nos chega ao consultório, em geral, os adotantes estão tomados por intensa ambivalência em ficar ou devolver aquela criança/adolescente. Portadores de intenso sofrimento ligado às fragilidades narcísicas, às frustrações sentidas em relação ao projeto de filiação, às decepções e ao ódio gerados a partir da intensa e, às vezes, longa trajetória de conflitos vividos na relação com aquele filho. Sem conseguirem ultrapassar os conflitos, a devolução avizinha-se como única saída possível, traduzindo a necessidade e a urgência de expulsar do psiquismo aquele sofrimento ainda indizível.

Dessa forma, experiências psíquicas ligadas às antigas e inomináveis fantasias e inquietudes em torno das origens diferentes entre a criança e o adulto; as histórias de vida e psíquicas de ambos, suas expectativas e motivações inconscientes; o "estranhamento" mútuo; e a ferida narcísica da infertilidade e do projeto de filiação, serão ingredientes frequentemente presentes no cenário da experiência clínica com a devolução.

Essa família se constituiu sob a ameaça imaginária dos adotantes a cerca de um segredo a respeito da história da mãe biológica do adolescente. Embora tivesse sido adotado aos 2 anos de idade, será na adolescência que os conflitos importantes e a violência surgirão na família, atualizando fantasmas ligados à sexualidade da mãe biológica e do adolescente, à herança genética, ao segredo e ao consequente sentimento de fracasso como pais. O adolescente, por sua vez, apresentava uma imensa necessidade de saber mais sobre suas origens, e seu comportamento anti-social e conflitivo com os pais ganha uma dimensão crescente e descontrolada. 
A adoção representava para esses pais, aspirações de filiação cultivadas em uma dimensão narcísica extrema, calcada na necessidade de gratidão por parte do adolescente, que não mais preenchia as exigentes expectativas a respeito dele. E a devolução então, revelava a eles o fracasso de um projeto idealizado e não alcançado. Por isso, quando eu os recebo, sentiam-se demasiadamente ambivalentes em relação ao desejo de reatar os vínculos. Feridos e ressentidos, transbordavam o ódio sobre ele, enquanto continuavam investindo afetuosamente nos seus cuidados, mesmo estando abrigado.

Ódio não apenas ao diferente. Ódio nascente da imensa ferida narcísica, relacionado com a ambivalência entre amor e ódio pelo mesmo objeto, ideia central para Freud na primeira tópica. Ódio nascente não apenas da percepção de que o objeto externo está relacionado à vivência de desprazer, mas também do registro deste desprazer suscitado por alguém que fornece também o prazer.

O ódio em sua magnitude, quando depositado na relação transferencial invade o analista, desconcerta-o. Via-me inundada por ele. Eu me perguntava se conseguiria sobreviver a ele... No entanto, surpreendia-me ser invadida por lembranças. Uma forma de conversa com a dimensão subjetiva em mim, diante da avalanche que recebia daqueles pais. Verdadeiro transbordamento sobre o analista, produzindo, de inicio apenas "descarga" uma vez que eles estavam impossibilitados de pensar.

O recurso à literatura surgia em minhas associações em forma de palavras, como recurso não apenas de sobrevivência, mas também para sustentar a rèverie necessária. E então, a lembrança do inestimável Guimarães Rosa (2001), em uma contundente passagem de Grande Sertão Veredas se impunha:

Se a gente... se a gente torna a encarnar renovado, eu cismo até que inimigo de morte pode vir como filho do inimigo. Mire veja: se me digo, tem um sujeito Pedro Pindó,...homem de bem por tudo em tudo, ele e a mulher dele....têm um filho duns dez anos....pois essezinho, essezim, desde que algum entendimento alumiou nele, feito mostrou o que é: pedido madrasto, azedo queimador, gostoso de ruim de dentro do fundo das espécies de sua natureza.... (p. 219).

A Psicanálise e sua clínica nos ensinam sobre a importância de abrirmos um campo de escuta e apostarmos na força da palavra que pode subverter o ato que, aqui, seria o da devolução. No acolhimento da angústia dos adotantes, o empréstimo de pensamentos e palavras, poderá vir em 
auxílio para a compreensão não apenas dos sentimentos subjacentes à descarga mas também dos sentimentos contra-transferenciais e da angustia que afeta o analista. Ao mesmo tempo, eu me via convocada a pensar: "como escutar esta devolução"? Pois muitas são as situações em que ela pode até se fazer necessária, ao traduzir sentimentos extremos de rejeição dos adotantes... ou então quando ela pode vir a representar um ganho para a criança dentro da lógica da menor perda. Eu também me perguntava: "como escutar a ambivalência que se veste de amores e ódios que se alternam com a rapidez de um trocar de roupas"? Sabia que teria que esperar pelas respostas, se é que elas viriam... Momentos de angustia, incertezas e desânimo me assombravam com frequência, fantasias de desistir do caso, sentimentos identificados em mim, análogos àqueles vivenciados pela família...

Sabemos que o processo de adoção dentro do contexto do Judiciário apresenta vicissitudes diferentes daquelas apresentadas na clínica psicanalítica. Há uma dissonância entre o modo como os diferentes campos epistemológicos da Psicanálise e do Direito, compreendem e lidam com a noção do tempo. O tempo experimentado na dimensão subjetiva, o do trabalho psíquico das elaborações necessárias, é muito mais lento e moroso do que aquele exigido para as decisões e encaminhamentos legais. Guardadas as especificidades de cada área, a noção de conflito também é compreendida diferentemente pela Psicanálise e pelo Direito. Enquanto a prática psicanalítica busca dispor o conflito em termos interpretáveis, a prática do Direito busca dispor o conflito em termo decidíveis, conforme a sua subsunção às normas jurídicas (Caffé, 2003). A Escuta e o acolhimento da intensa ambivalência é necessária para a sustentação da tensão conflituosa, entendendo-se essa tensão como uma dimensão constituinte do mal-estar fundante da subjetividade.

Diante da pressão da promotoria para uma definição sobre o retorno do adolescente para casa, fez-se necessária uma intervenção "clínica-estendida", e assim, compareci a uma reunião na Rede de serviços com a presença da Promotora que conduzia o caso, no sentido de sustentar a importância de se esperar o tempo interno de elaborações mínimas dos protagonistas ( dos adotantes e da adolescente). Tempo necessário também para minhas elaborações, e por que não para ventilar meus próprios pensamentos....

O adolescente por sua vez, encontrava-se institucionalizado, hipermedicado como forma de contenção dos impulsos agressivos e dos sentimentos depressivos. Sem contar com um acompanhamento específico, e a meu ver, sem saberem o que fazer com ele, os adotantes e a Rede de assistência social pensavam em interná-lo para uma desintoxicação... Diante de tantas demandas, o analista pode se ver ou se sentir ele mesmo intoxicado, comprometendo a acuidade da escuta. O trabalho compartilhado com outros profissionais que possam com ele formar uma espécie de "rede" 
passa a ser então fundamental, para a sobrevivência não apenas do método e da Escuta como do "próprio analista".

Mas, no que consiste a sobrevivência do analista? O que significa sobreviver? Roussillon (2017) dirá tratar-se de "uma sobrevivência subjetiva, da sobrevivência do objeto (analista) pela subjetividade do sujeito, de uma sobrevivência na experiência, nos afetos do sujeito e para o sujeito" (p.420). E acrescenta sobre a importância do objeto continuar a se mostrar criativo em sua resposta ou reação. Manter-se vivo é manter-se criativo, dando-se a conhecer como outro-sujeito, independente do sujeito, fora do alcance de sua onipotência. E sublinha que "o destino da destrutividade terá então um encaminhamento conforme o grau de sobrevivência do objeto". (idem).

Os pais seguiram cada qual um acompanhamento clínico individual e eu iniciei o atendimento do adolescente, uma vez que ele havia estabelecido rudimentos de uma transferência positiva comigo e seu acompanhamento clínico passou a ser considerado por todos como uma prioridade. Antes do inicio do atendimento propriamente dito, eu havia conduzido o trabalho familiar de orientação para a revelação das origens do adolescente, algo que vinha sendo pedido por ele há alguns anos e os pais, embora motivados a conversar sobre isso, não sabiam como fazê-lo. Eu apostava que seria o equivalente a buscar o inicio de uma meada, um fio condutor para a narrativa histórica, a historicização fundamental para a instalação de processos de elaboração e simbolização do adolescente. Diferentemente da recuperação de dados históricos, a construção de uma narrativa acerca das origens, transformação do vivido em experiência subjetivada - ideia que já desenvolvi anteriormente (Ghirardi, 2015) e em cuja temática sinto-me apoiada por alguns colegas psicanalistas (Peiter, C. (2012), S. Penot, B.(1975), entre outros) - carrega a potência de colocar palavras onde vigora o ato. Ato que carrega tantas vezes uma dimensão do traumático, em cuja "carona" viaja a possibilidade da devolução na adoção.

Nesse paciente, preocupava-me a forma de expressão privilegiada de seus sentimentos, dada pelos comportamentos explosivos, descargas verbais e motoras, denotando pouca elaboração psíquica e referências simbólicas. Senti necessidade da inclusão no setting, de um objeto intermediário, que pudesse ser usado como uma espécie de mediação entre o discurso tantas vezes vazio e os cortes que ele próprio imprimia em seu corpo, na busca por "sentir-se vivo".

E assim, vimos trabalhando na montagem de um álbum a respeito de sua história, utilizado como um recurso narrativo para as necessárias aquisições (elaborações) da simbolização acerca de suas dores... 


\section{Referências:}

Caffé, M. (2003) Psicanálise e Direito. São Paulo, Quartier Latin.

Freud, S. (1919) O Estranho. Rio de Janeiro, Imago, ESB, 1976.v.XII.

Ghirardi, M.L.A.M. (2015) Devolução de Crianças Adotadas: um estudo psicanalítico. São Paulo, Primavera Editorial.

Nosek, L. (2017) A Disposição para o Assombro. São Paulo, Perspectiva.

Peiter, C. (2011) Adoção, Vínculos e Ruptura: do abrigo à família adotiva. São Paulo, Zagodoni Ed.

Penot, B. (1975) A Identidade em questão: reflexões sobre adolescência e psicose. Publicado originalmente na "Revue de Neuropsychiatre Infantile", 23 (12): 833-842. Trad, Nilde P. Franch.

Rosa, G. ( 2001) Grande Sertões: Veredas. R.Janeiro, Nova Fronteira, 19ª Ed.,7ª impressão.

Todorov, T. (2016) A Conquista da América. São Paulo, Editora WMF Martins Fontes Ltda. (trabalho original publicado em 1983). 